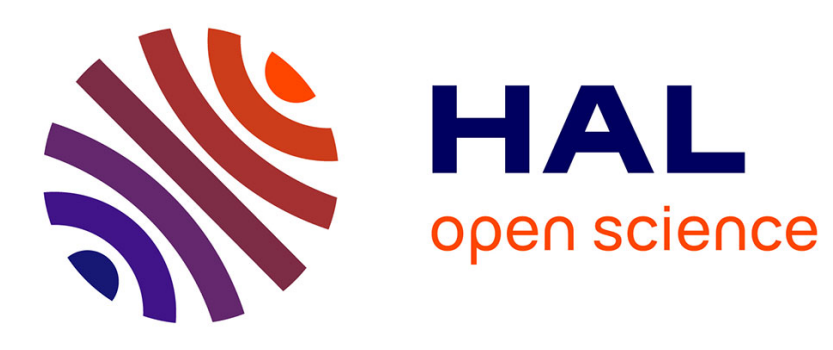

\title{
A yeast-based assay to isolate drugs active against mammalian prions
}

Stéphane Bach, Déborah Tribouillard, Nicolas Talarek, Nathalie Desban, Marc Blondel

\section{To cite this version:}

Stéphane Bach, Déborah Tribouillard, Nicolas Talarek, Nathalie Desban, Marc Blondel. A yeastbased assay to isolate drugs active against mammalian prions. Methods, 2006, 39 (1), pp.72-77. 10.1016/j.ymeth.2006.04.005 . hal-02134947

\section{HAL Id: hal-02134947 \\ https://hal.science/hal-02134947}

Submitted on 27 May 2019

HAL is a multi-disciplinary open access archive for the deposit and dissemination of scientific research documents, whether they are published or not. The documents may come from teaching and research institutions in France or abroad, or from public or private research centers.
L'archive ouverte pluridisciplinaire HAL, est destinée au dépôt et à la diffusion de documents scientifiques de niveau recherche, publiés ou non, émanant des établissements d'enseignement et de recherche français ou étrangers, des laboratoires publics ou privés. 
A yeast-based assay to isolate drugs active against mammalian prions

Stéphane Bach ${ }^{1}$, Déborah Tribouillard ${ }^{2}$, Nicolas Talarek ${ }^{3}$, Nathalie Desban ${ }^{2}$ and Marc Blondel ${ }^{2} *$

${ }^{1}$ C.N.R.S., Station Biologique, UPS2682, Place G. TEISSIER, 29680 Roscoff, Bretagne, France

${ }^{2}$ C.N.R.S., Station Biologique, UMR7150, Place G. TEISSIER, 29680 Roscoff, Bretagne, France

3 Department of Pediatric Oncology, Dana-Farber Cancer Institute, Harvard Medical School, Boston, Massachusetts, 02115, USA

* to whom correspondence should be addressed: blondel@,sb-roscoff.fr fax.: + $33(0) 2982923$ 42, tel.: + $33(0) 298292322$

Running title: A yeast-based antiprion screening assay

Key words: prion, screening assay, budding yeast, [PSI+] ,[URE3], ERG6. 


\begin{abstract}
Recently, we have developped a yeast-based (Saccharomyces cerevisiae) assay to isolate drugs active against mammalian prions. The initial assumption was that mechanisms controlling prion appearance and/or propagation could be conserved from yeast to human, as it is the case for most of the major cell biology regulatory mechanisms. Indeed, the vast majority of drugs we isolated as active against both $[P S I+]$ and $[U R E 3]$ budding yeast prions turned out to be also active against mammalian prion in three different mammalian cellbased assays. These results strongly argue in favour of common prion controlling mechanisms conserved in eukaryotes, thus validating our yeast-based assay and also the use of budding yeast to identify antiprion compounds and to study the prion world.
\end{abstract}

\title{
1. Introduction
}

To date, there is no efficient treatment for prion-based diseases [1,2]. Designing efficient therapeutic approaches is made difficult by a number of problems. First, the nature of the infectious agent (the prion) is not fully and unambiguously identified. Second, the mechanisms of prionmediated toxicity are still poorly understood. Third, the diagnostic is very difficult to establish firmly and can be made usually only at later stages, after the onset of severe clinical symptoms. This point raises the important question whether the neurodegenerative process can still be reversed efficiently at this stage and even if so, whether it is not already too late to provide a real therapeutic benefit to the patient. Interestingly, a partial but significant answer to this last question has been obtained using mice where the PRNP gene (encoding for PrP protein) can be turned off. The 
depletion of $\operatorname{PrP}^{\mathrm{C}}$ from neurons of prion-infected mice not only prevented progression of clinical disease, but also reversed spongiosis [3]. Thus, therapy aimed at reducing endogenous $\operatorname{PrP}^{\mathrm{C}}$ or $\operatorname{Pr} \mathrm{P}^{\mathrm{Sc}}$ levels may well be effective after the appearance of symptoms.

Based on the assumption that $\operatorname{PrP}^{\mathrm{Sc}}$ corresponds to (or is part of) the pathogenic entity, or at least the infectious agent, various avenues for finding therapies for prion-based diseases, aiming at reducing $\operatorname{PrP}^{\mathrm{C}}$ or $\operatorname{PrP}^{\mathrm{Sc}}$ levels, are currently explored. Among these approaches are active or passive vaccinations. These are based on the observations that anti-PrP antibodies inhibit formation of $\operatorname{PrP}^{\mathrm{Sc}}$ in a cell-free system [4] and also that anti-PrP antiserum reduces the infectious titer of hamster brain homogenates about a hundredfold [5]. Other approaches aim at the identification of compounds able to stabilize $\operatorname{PrP}^{\mathrm{C}}$, destabilize $\operatorname{PrP}^{\mathrm{Sc}}$, or prevent conversion from $\operatorname{PrP}^{\mathrm{C}}$ to $\operatorname{PrP}^{\mathrm{Sc}}$ and thereby decrease the level of $\mathrm{PrP}^{\mathrm{Sc}}$. Some of these approaches are based on the use of cell-free systems [6-9], whereas other are based on the use of mammalian cells chronically infected with $\operatorname{PrP}^{\mathrm{Sc}}[10-13]$. In these last assays, the presence of $\mathrm{PrP}^{\mathrm{Sc}}$ is monitored by the proteinase $\mathrm{K}$ sensitivity assay. Although clearly useful, these various cell-based assays are not easily amenable to highthroughput screening, in particular because experiments have to be done in highly secured laboratories. The possibility to screen large chemical libraries appears to be important. For these reasons, we developped a rapid and economical budding yeast-based two step assay to screen for antiprion drugs [14]. Our initial assumption was that mechanisms controlling prion appearance and/or propagation could be conserved from yeast to human. Indeed, most of the drugs we isolated as active against budding yeast (Saccharomyces cerevisiae) prions turned out to be also active to promote $\mathrm{PrP}^{\mathrm{Sc}}$ clearance in three different mammalian cell-based assays [10-13]. In addition, most of the compounds isolated as active in mammalian cell-based assays that we tested were also found to be active in the yeast-based assay [14]. Taken together, these results strongly suggest the existence of prion controlling mechanism(s) conserved from yeast to human, thus validating yeast 
as an appropriate model to study prion appearance and propagation but also the yeast-based approach to efficiently detect compounds active against mammalian prion from large chemical libraries. Furthermore the yeast-based method can also be used to rapidly make comprehensive structure activity relationship (SAR) studies for already identified active molecules.

The general principles of our two steps yeast-based method have been already described elsewhere [14]. Briefly the two steps are based on the use of a white or red colonies coloration system. Yeast cells, when unable to synthetize adenine due to inactivation of the $A D E 1$ or $A D E 2$ genes (two genes encoding for enzymes involved in the adenine biosynthesis pathway), produce red colonies on rich (YPD) medium because of the accumulation of metabolic by-products of the adenine biosynthesis pathway (these metabolic by-products, after oxydation, appear red). The first step of the screening is based on the $[\mathrm{PSI}+]$ phenotype which corresponds to the prion state of Sup35p, a subunit (also called eRF3) of the eukaryotic release factor. In $[P S I+]$ cells, Sup35p is mainly sequestered into protein aggregates and thus unavailable to function in translation termination. As a result, ribosomes have an increased tendency to read through stop codons. A convenient reporter system to monitor this heritable change in protein synthesis fidelity is the use of ade1-14 allele in which an opal stop codon (UGA) replaces the UGG (Trp) codon at position 240 in the open reading frame (ORF) of the $A D E 1$ gene [15]. Because of the ability of ribosomes to read through stop codons in $[P S I+]$ cells, these cells produce functional Ade1p enzyme and thus are able to grow on adenine-deficient medium (SD-Ade) and to form white colonies on rich medium, in spite of being genetically auxotrophic for adenine. In contrast, in [psi-] cells where Sup35p is in its normal soluble form, translation of the ade1-14 allele terminates at the opal codon hence preventing cells from growing on SD-Ade and leading to red colonies on YPD medium. Thus, starting from $[P S I+]$ cells forming white colonies on YPD, the criteria used for drug libraries screening is the ability of the tested molecules, to shift colonies coloration from white to red. A secondary screen 
based on the [URE3] prion, which correspond to the prion state of Ure2p protein, was implemented by adapting a previously designed strain [16]. Briefly, the ORF of the DAL5 gene was replaced by that of the $A D E 2$ gene in an ade2A, [URE3] strain. The DAL5 gene is not transcribed when Ure $2 \mathrm{p}$ is active. Hence, if Ure2p is inactivated by a prion mechanism ([URE3] cells), ADE2 is actively transcribed, resulting in the formation of white colonies on YPD medium whereas [ure3-0] cells form red colonies.

\section{Description of method}

\subsection{Yeast strains}

Convenient strains for the primary $[P S I+]$-based screen are "weak" and "strong" variants of the 74-D694 strain [17]. A strong 74-D694 strain usually gives better results than a weak 74-D694 strain because of the clearer difference in coloration between $[\mathrm{psi}-]$ and $[\mathrm{PSI}+]$ colonies due to the strength of the prion strain. Conversely, the use of a weak variant can be considered, as the prion may be less stable and thus easier to eliminate (Sup35p is less intensively aggregated). Standard yeast growth conditions and genetic manipulations are as described $[18,19]$. The cornerstone of the method is the use of small sterile filters similar to those used for antibiograms. $[P S I+]$ cells (forming white colonies) are spread on a YPD solid medium (12 cm X 12cm square Petri plates are the most convenient to test many different drugs on the same plate and to have an easy square grid that allows to test 30 different compounds together with controls -see figure 1-). These small (6 mm of diameter) filters (Schleicher and Schuell, references: 10321260 -for volumes up to $20 \mu 1$ - or 10321860 -for volumes up to $8 \mu \mathrm{l}$-) are deposited on the top of the agar surface. A different 
compound from the chemical library to screen is spotted on each filter. This compound then diffuses in the surrounding medium, establishing a full concentration gradient. The size of the halo of red colonies should thus be proportional to the activity of the corresponding compound, as long as the compounds have the same ability to diffuse into the agar medium. In addition, drugs active against yeast prions but toxic at high concentration will result in a halo of non growing cells surrounded by a crown of red colonies (Fig. 1B). Thus, in a simple experiment, semi-quantitative information on activity and toxicity can be obtained. The quantity of $[P R I O N+]$ cells to spread on Petri plates has been optimized for each strain as indicated below.

Budding yeast cells exhibit a limited permeability to a number of chemical compounds, probably because, in addition to a plasma membrane, they are also surrounded by a cell wall. In addition, compared to higher eukaryotic cells, yeast cell membrane has a special lipid composition. Several genetic tricks allow to circumvent this permeability problem. One example is the inactivation of one or several of the $P D R$ genes encoding ATP-binding cassette (ABC) transporters (or transcription factors controlling their expression) which in yeast, by mediating drug efflux as in higher eukaryotes, are involved in Multi Drug Resistance (MDR) [20]. Other ways to increase the limited permeability of yeast cells aim to alter membrane and/or cell wall composition thereby directly affecting cell permeability. In this category lies the inactivation of the ERG6 gene. The ERG6 gene encodes for a sterol methyltransferase which acts in the last steps of ergosterol biosynthesis. Limited permeability of yeast cells to small molecules is thought to be related, at least in part, to the unique sterol composition of fungal membranes, which are enriched in the steroid ergosterol. erg6 cells thus have an altered membrane composition and, as a result, exhibit increased permeability to a growing list of chemical compounds, in particular to small lipophilic drugs $\left[{ }^{21}\right]$. For example, the $26 \mathrm{~S}$ proteasome inhibitor MG132 or the vesicular traffic inhibitor Brefeldin A are not active in wild-type (WT) cells whereas they are very active when applied to 
erg64 cells [22,23]. For this reason, we decided to delete the ORF of the ERG6 gene in a strong variant of 74-D694. This strain is auxotrophic for tryptophan (it contains the trp1-289 allele of the TRP1 gene, Table 1). Inactivation of the TRP1 gene is synthetically lethal (or at least synthetically sick) with inactivation of the ERG6 gene ([24] and our personal observations), most probably because ergosterol is required for targeting of tryptophan permease to the yeast plasma membrane [25]. For these reason, we replaced the ORF of the ERG6 gene by the TRP1 genetic marker therefore ensuring that $\operatorname{erg} 64$ transformants are able to synthetize their own tryptophan. In addition, the absolute genetic link between the ERG6 gene inactivation and the TRP1 genetic marker allows easier genetic crosses with trp1 1 strains as all erg6 segregants obtained are also TRP1wt. Hence, the genotype of the erg64 [PSI+] "strong" strain (STRg6) we created is as follow: Mata, ade1-14, trp1-289, his3 200 , ura3-52, leu2-3,112, erg6::TRP1, [PSI+].

For the secondary screen, we adapted a rationale previously used [16] in a CC34 strain (Mata, ade2-1, trp1-1, leu2-3,112, his3-11,15, ura2::HIS3, [URE3] strain [26]). In this strain, the ORF of the DAL5 gene was replaced by that of the $A D E 2$ gene. In addition, the ade2-1 gene was replaced by the KanMX marker to avoid possible interference of a putative $[\mathrm{PSI+}]$ appearance on red/white colony coloration in this strain. Finally, the ORF of the ERG6 gene was replaced by the TRP1 marker in order to increase cell permeability. In this NT35 strain (Mata, ade2-1::KanMX, trp1-1, leu2-3,112, his3-11,15, ura2::HIS3, dal5::ADE2, erg6::TRP1, [URE3]), if Ure2p is inactivated by a prion mechanism ([URE3] cells), $A D E 2$ is actively transcribed, resulting in the formation of white colonies on YPD medium whereas [ure3-0] cells form red colonies.

Concerning the storage and the use of the erg64 strains generated, it is important to note that, probably due to their altered plasma membrane lipid composition, they exhibit a number of pleiotropic phenotypes, including low transformation efficiency, reduced growth rate and low ability to recover from stationary phase [24]. These phenotypes are largely dependent on the genetic 
background. For example, the NT35 strain grows nearly like isogenic $W T$ cells whereas the STRg6 strain exhibits a significantly reduced growth rate and, in addition, recovers very poorly from even a very short passage in stationary phase. For this reason, the STRg6 strain should be kept in exponential phase of growth by restreaking it every two days on a fresh synthetic medium lacking tryptophan (SD-Trp) and incubated at $25^{\circ} \mathrm{C}$.

\subsection{Practical approach of the screening assay}

The quantity of STRg6 (primary [PSI+]-based screen) and NT35 (secondary [URE3]-based screen) cells to spread have been optimized in order to have a nice layer of colonies: an excessive number of colonies reduces the possible number of generation for the cells which are spread (therefore potentially reducing the chance to have an efficient cure) whereas an insufficient number of cells decreases the possibility to obtain a nice, clear and sharp red halo. About 350-400 $\mu$ of a STRg6 liquid YPD grown at $25^{\circ} \mathrm{C}\left(\mathrm{OD}_{600 \mathrm{~nm}}=0.5\right)$ should be spread on a $144 \mathrm{~cm}^{2}(12 \mathrm{~cm} \mathrm{X} 12 \mathrm{~cm})$ square Petri plate (CML, reference: BP124S14) whereas, in the case of NT35, 150-200 $\mu 1$ of a liquid YPD grown at $25^{\circ} \mathrm{C}\left(\mathrm{OD}_{600 \mathrm{~nm}}=0.5\right)$ should be used.

The medium used is classical YPD medium (see below). It appears that the type of yeast extract used for medium preparation can have some effect on the intensity of the red coloration of [prion-] colonies. The optimal coloration was obtained with Fisher Scientific Labosi yeast extract (reference: A8080540). Another modification to the YPD medium recipe is the addition of subefficient dose of guanidine hydrochloride $(\mathrm{GuHCl})$. $\mathrm{GuHCl}$ is a chemical inhibitor of Hsp104p [2729], a protein chaperone essential for propagation of prion in budding yeast [17] by leading to prion aggregates shearing, therefore allowing seeds "replication". Inhibition of Hsp104p and curing effect requires treatment with 2 to $5 \mathrm{mM}$ of $\mathrm{GuHCl}$ for cells maintained in exponential phase of growth 
for at least six generation times. Hsp104p is not a good screening target for antiprion assays as it does not seem to be conserved in vertebrates. For this reason, we tested the effect of adding subeffective doses of GuHCl in the YPD medium [14]. We found that the activity of all the compounds we isolated so far is strongly synergized by such a sub-effective dose of GuHCl. This synergy suggests that all these active molecules act on pathway(s) distinct from the GuHCl-sensitive Hsp104p pathway. As most of these drugs also turned out to be active to promote mammalian prion clearance in the three mammalian cell-based assays described above, we believe these pathways to be conserved from yeast to human (see Discussion). A GuHCl dose of $200 \mu \mathrm{M}$ (about 5 to $10 \%$ of the active dose for inhibition of Hsp104p) was determined as optimal screening conditions (enhanced sensitivity and good white/red contrast). Higher doses, although increasing the activity of compounds, also enhances the background coloration (which turns from white to pink). Thus the recipe we use for YPD medium is as follows (for one liter): $10 \mathrm{~g}$ Bacto Yeast Extract (Fisher Labosi Scientific, reference: A8080540), 20 g Bacto Peptone (Difco, reference: 211677), 20 g DGlucose monohydrate (Fluka, reference: 49160), 20 g Bacto Agar (Difco, reference: 214010) -for solid medium-, completed to one liter with distilled water. The media are sterilized by autoclaving for 20 minutes at $120^{\circ} \mathrm{C}$. After autoclaving, agar containing media are cooled down to about 50$60^{\circ} \mathrm{C}, \mathrm{GuHCl}(650 \mu \mathrm{l}$ of a $300 \mathrm{mM}$ stock solution in DMSO to reach a final concentration of 200 $\mu \mathrm{M})$ is added and the plates are poured.

A grid with 32 positions for positioning the small filters was also optimized: it allows to test 30 different compounds ( 2 to $5 \mu \mathrm{l}$ of a $10 \mathrm{mM}$ solution -or $1 \mathrm{mg} / \mathrm{ml}$ for natural extracts- in DMSO) unambiguously, in addition to one negative control (DMSO, the vehicle of most of the chemical libraries compounds, top left filter) and one positive control ( $\mathrm{GuHCl}, 5 \mu \mathrm{l}$ of a $300 \mathrm{mM}$ solution, bottom right filter) per Petri plate. 
A very convenient and popular way to organize chemical compound collection is to use 96 wells plates where compounds ( 80 per plate) are displayed one in each position, except in the first and last column (dedicated to controls in automatized screening assays). Usually, the compounds are at a concentration of $10 \mathrm{mM}$ (sometimes $5 \mathrm{mM}$ ) and dissolved in DMSO. It is convenient to organize a conversion grid between the 96 -wells plate ( 80 different compounds) and the Petri plate (30 different positions). Using these various adaptations of the system, a single person can manually test up to 500 molecules a day.

The Petri plates are then incubated at $25^{\circ} \mathrm{C}$ for three days and then incubated for one to three days at $4{ }^{\circ} \mathrm{C}$ to allow reinforcement of the red coloration. Indeed, AIR, a metabolic byproduct which is accumulated when the adenine biosynthesis pathway is interrupted at the level of the Adelp or Ade $2 p$ enzymes, needs to be oxydized in order to appear red. This oxydation occurs mainly in stationary phase which occurs more rapidly at $4{ }^{\circ} \mathrm{C}$. After incubation at $4{ }^{\circ} \mathrm{C}$, Petri plates can be observed and directly digitalized on a scanner.

A picture of a convenient system as currently used in the laboratory is shown in Fig. 1A.

\subsection{Elimination of false positives}

A number of false positives including, in particular, compounds interfering with the white/red reporter system, could potentially be picked up. For example, in principle, all drugs able to inhibit the enzymatic activity or expression of the Ade1p or Ade $2 p$ enzymes should also lead to the formation of red colonies. These false positives are easy to eliminate as their effect on colony coloration should be reversed when drugs are removed. Indeed, by just picking cells from colonies in the red halos (using a sterile loop), washing them in drug-free sterile water or YPD medium and then streaking them on a fresh, drug-free, YPD medium, it is possible to observe whether the tested 
compounds act directly on the reporter system (Fig. 1C). If cells from the initial red colonies now form white colonies, the corresponding chemical compound is interfering with the colorimetric system. In contrast, if they (all, most of them or at least a large fraction) still form red colonies, the corresponding drug probably acted on yeast prions. To confirm this, the curing effect should also be checked directly, for example in the $[P S I+]$-based primary screen by determining the aggregation state of the prion protein using ultracentrifugation [15]. Whereas in extracts of $[P S I+]$ cells, most of the Sup35p protein is found in the pellet fraction, it should be largely found in the soluble fraction in [psi-] cell extracts. In addition, to confirm the curing effect, other reporter systems can be used to monitor the prion state including the ureidosuccinic acid (USA) reporter system for [URE3] [15]. Indeed, as the [URE3] prion enables ura2 cells, which are normally unable to grow on medium lacking uracil, to import USA (via the Dal5p transporter) and make uracil, [URE3] strains (like CC34, Table 1) grow on USA-containing medium $(15 \mathrm{mg} / \mathrm{l})$ whereas [ure3-0] cells do not. By comparing the number of colonies in a minimal medium supplemented with uracil (SD+Ura) where both [URE3] and [ure3-0] cells grow and on USA medium where only [URE3] cells grow, the curing effect of the considered compound can be evaluated.

\subsection{Testing active compounds against mammalian prion}

Once isolated from the chemical libraries, the few compounds active against both yeast prions have to be tested against mammalian prion. This can be done using first the three ex vivo mammalian cell-based assays mentioned in the introduction. The use of all the three different systems should be considered as they exhibit significant differences (murine versus sheep-based prions, epithelial versus neuroglial cells, murine versus rabbit cells) which make them attractive. Hence, an activity in each these three different systems provides a lot of confidence concerning the 
activity of the corresponding compound against mammalian prion. Indeed, by comparing activity of various compounds able to lead to $\mathrm{PrP}^{\mathrm{Sc}}$ clearance in both murine $\mathrm{N} 2 \mathrm{a}$ cells infected by murine prion (RML or 22L prion strains) and rabbit Rov9 cells infected with sheep scrapie, it has been shown very recently that the mouse N2A cell-based system is both clearly the most sensitive system, but also, at the same time, the less stringent [30]. Among 41 drugs active in the N2a cellbased assays tested, only three turned out to be also clearly active in the Rov9 cell-based system. An activity in the Rov9-based system thus appears to be a good indicator. In addition, in the Rov9based system, when drugs are applied to cell culture, cells already reached confluency, thus these are not growing cells which could appear as a better model for non growing cells like neurons.

The few molecules active both against yeast prions and in mammalian cell-based assays should then be tested in vivo in murine- (or generally rodent-) based models for prion-based diseases. A number of different models exist in which the nature of the infecting prion (ovine scrapie, murine scrapie, human $\operatorname{PrP}^{\mathrm{Sc}} \ldots$ ), the mode of infection (intraperitoneal or intracerebellar injection) or the level of $\operatorname{PrP}$ expression (constitutively or inducibly expressed) vary [31]. Interestingly, by varying the time of the beginning of the treatment (before, during or after the infection or even after the beginning of the first clinical symptoms), various effects can be tested (activity in prophylaxis, to promote reversion of the clinical signs and eventually on the survival).

\section{Concluding remarks}

Most of the compounds isolated so far using the yeast-based method turned out to be also active against mammalian prion, at least in the various cell-based assays described before ([14] and N. Desban, D. Vilette and M. Blondel, unpublished results). Conversely, most molecules already 
known as active to promote mammalian $\mathrm{PrP}^{\mathrm{Sc}}$ clearance and that were tested were also found to be active against both $[P S I+]$ and [URE3] yeast prions [14]. Hence, the yeast method clearly allow high throughput approaches as it is fast, efficient and cheap. Furthermore, the turnover of the method can be increased significantly by automatizating various steps like sterile filters deposition and drugs distribution. Taken together, these results validate the use of this yeast system to screen large chemical libraries for compounds potentially active for the treatment of prion-based diseases in mammals.

The fact that most of the molecules isolated in the yeast-based assay are also active against mammalian prion provides a strong support to the hypothesis that they probably act on common prion controlling mechanims, which are conserved from yeast to human. These observations clearly validate the use of budding yeast to study mechanisms controlling prion appearance, propagation and transmission. The drugs could thus serve as bait to purify the conserved target(s), for example by affinity chromatography on immobilized drugs or by using three-hybrids approaches.

To conclude, it would be very interesting to test some of these compounds in models of other, neurodegenerative or not, amyloid fiber-based diseases as it is well possible that common control mechanisms exist.

\section{Acknowledgements}

This work was carried out in the laboratory of Laurent Meijer who is warmly acknowledged for his continuing support and helpful discussions. Laurent Meijer and Sven J. Saupe are acknowledged for critical proofreading of the manuscript. We thank members of our laboratories for helpful discussions. This research was supported by the following grants: a GIS "Infections à prion", a PRIR from the "Conseil Régional de Bretagne", an ACI "Jeune Chercheur" from the 
french "Ministère de la Recherche", from "CRITT Santé Bretagne" and an "Ingénieur de valorisation " fellowship from the CNRS.

\section{References}

[1] C. Weissmann, A. Aguzzi, Annu. Rev. Med. 56 (2005) 321-344.

[2] G. Mallucci; J. Collinge, Nat. Rev. Neurosci. 6 (2005) 23-34.

[3] G. Mallucci, A. Dickinson, J. Linehan, P. C. Klohn, S. Brandner, J. Collinge, Science 302 (2003) 871-874.

[4] M. Horiuchi, B. Caughey, EMBO J. 18 (1999) 3193-3203.

[5] R. Gabizon, M.P. McKinley, D. Groth, S.B. Prusiner, Proc. Natl. Acad. Sci. USA 85 (1988) 6617-6621.

[6] S. Supattapone, H.O. Nguyen, F.E. Cohen, S.B. Prusiner, M.R. Scott, Proc. Natl. Acad. Sci. USA 96 (1999) 14529-14534.

[7] C. Soto, R.J. Kascsak, G.P. Saborio, P. Aucouturier, T. Wisniewski, F. Prelli, R. Kascsak, E. Mendez, D.A. Harris, J. Ironside, F. Tagliavini, R.I. Carp, B. Frangione, Lancet 355 (2000) 192-197.

[8] Y. Cordeiro, L.M. Lima, M.P. Gomes, D. Foguel, J.L. Silva, J. Biol. Chem. 279 (2004) 5346-5352.

[9] U. Bertsch, K.F. Winklhofer, T. Hirschberger, J. Bieschke, P. Weber, F.U. Hartl, P. Tavan, J. Tatzelt, H.A. Kretzschmar, A. Giese, J. Virol. 79 (2005) 7785-7791.

[10] K. Doh-Ura, T. Iwaki, B. Caughey, J. Virol. 74 (2000) 4894-4897.

[11] C. Korth, B.C. May, F.E. Cohen, S.B. Prusiner, Proc. Natl. Acad. Sci. USA 98 (2001) 98369841.

[12] D. Vilette, O. Andreoletti, F. Archer, M.F. Madelaine, J.L. Vilotte, S. Lehmann, H. Laude, Proc. Natl. Acad. Sci. USA 98 (2001) 4055-4059.

[13] F. Archer, C. Bachelin, O. Andreoletti, N. Besnard, G. Perrot, C. Langevin, A. Le Dur, D. Vilette, A. Baron-Van Evercooren, J.L. Vilotte, H. Laude, J. Virol. 78 (2004) 482-490.

[14] S. Bach, N. Talarek, T. Andrieu, J.M. Vierfond, Y. Mettey, H. Galons, D. Dormont, L. Meijer, C. Cullin, M. Blondel, Nat. Biotechnol. 21 (2003) 1075-1081.

[15] Y.O. Chernoff, S.M. Uptain, S.L. Lindquist, Methods Enzymol. 351 (2002) 499-538.

[16] M. Schlumpberger, S.B. Prusiner,I. Herskowitz, Mol. Cell. Biol. 21 (2001) 7035-7046.

[17] Y.O. Chernoff, S.L. Lindquist, B. Ono, S.G. Inge-Vechtomov, S.W. Liebman, Science 268 (1995) 880-884.

[18] F. Sherman, Methods Enzymol. 350 (2002) 3-41.

[19] C. Guthrie, G.R. Fink, Guide to Yeast Genetics and Molecular Biology; Academic Press, San Diego, 1991.

[20] B.E. Bauer, H. Wolfger, K. Kuchler, Biochim. Biophys. Acta 1461 (1999) 217-236.

[21] R. Emter, A. Heese-Peck, A. Kralli, FEBS Lett. 521 (2002) 57-61.

[22] D.H. Lee, A.L. Goldberg, J. Biol. Chem. 271 (1996) 27280-27284.

[23] T.R. Graham, P.A. Scott, S.D. Emr, EMBO J. 12 (1993) 869-877. 
[24] R.F. Gaber, D.M. Copple, B.K. Kennedy, M. Vidal, M. Bard, Mol. Cell. Biol. 9 (1989) 3447-3456.

[25] K. Umebayashi, A. Nakano, J. Cell Biol. 161 (2003) 1117-1131.

[26] E. Fernandez-Bellot, E. Guillemet, C. Cullin, EMBO J. 19 (2000) 3215-3222.

[27] S.S. Eaglestone, L.W. Ruddock, B.S. Cox, M.F. Tuite, Proc. Natl. Acad. Sci. USA 97 (2000) 240-244.

[28] P.C. Ferreira, F. Ness, S.R. Edwards, B.S. Cox, M.F. Tuite, Mol. Microbiol. 40 (2001) 1357-1369.

[29] G. Jung, D.C. Masison, Curr. Microbiol. 43 (2001) 7-10.

[30] D.A. Kocisko, A.L. Engel, K. Harbuck, K.M. Arnold, E.A. Olsen, L.D. Raymond, D. Vilette, B. Caughey, Neurosci. Lett. 388 (2005) 106-111.

[31] T. Baron, Trends Mol Med 8 (2002) 495-500. 


\section{Figure legends}

\section{Figure 1: .}

A: Screening system: a square Petri plate $(12 \mathrm{~cm} \times 12 \mathrm{~cm})$ containing YPD solid medium supplemented with $\mathrm{GuHCl}$ to a final concentration of $200 \mu \mathrm{M}$ is positioned onto a 32 position grid. Small filters (similar to the one used for antibiograms) are added on the top of agar surface according to the grid. Compounds from a 96 wells plate-organized chemical library are deposited (2 to $5 \mu \mathrm{l}$ of a 5 to $10 \mathrm{mM}$ solution in DMSO) one on each filter except on the top left filter where the negative control (DMSO, the compounds vehicle) and on the bottom right filter where the positive control (GuHCl, $5 \mu 1$ of a $300 \mathrm{mM}$ solution in DMSO) are added. Plates are then incubated for three days at $25^{\circ} \mathrm{C}$, followed by one to three days at $4^{\circ} \mathrm{C}$ and then photographed. On the example shown, in addition to the positive control (bottom right filter), one compound (X) is active (a halo of red colonies appears around the filter) whereas several others are toxic (halos of non growing cells that appear brown/orange - the color of the YPD medium- around the filter).

B: In one simple experiment a compound toxic at high concentration but active at lower concentration can be visualized. The molecules deposited on the top left and the bottom filters are toxic at high concentration but, in contrast to the last one, the first one is active against yeast prions at sub-toxic concentration: a crown of red colonies appears around a halo of non growing cells (which reveals the orange/brown color of the medium). Note that the compound deposited on the top right filter is active and not toxic, even at the higher concentration (in the immediate vicinity of the filter).

C: A simple assay to eliminate false positive compounds interfering with the colorimetric assay. Cells from the red halo are picked up with a sterile loop, washed in sterile water and then streaked 
on drug-free YPD medium. If they form white colonies (top panel), it means that the corresponding drug was acting on the colorimetric reporter system (for example by inhibiting Ade1p or Ade $2 p$ enzymes). In contrast, if these cells form red colonies, the corresponding molecule is a good candidate for being active against yeast prions. 


\section{Table 1: Strain list}

Strain name Relevant genotype

source

74-D694 Mata, ade1-14, trp1-289, his34200, ura3-52, leu2-3,112, [PSI+]

STRg6 Mata, ade1-14, trp1-289, his34200, ura3-52, leu2-3,112, $\operatorname{erg} 6:: T R P 1,[P S I+]$

CC34 Mata ade2-1, trp1-1, leu2-3,112, his3-11,15, ura2::HIS3, [URE3]

NT34 Mata ade2-1, trp1-1, leu2-3,112, his3-11,15, ura2::HIS3, dal5::ADE2, [URE3]

SB35 Mata, ade2-1, trp1-1, leu2-3,112, his3-11,15, ura2::HIS3, dal5::ADE2, erg6::TRP1, [URE3]

NT35 Mata ade2-1::KanMX, trp1-1, leu2-3,112, his3-11,15, ura2::HIS3, dal5::ADE2, erg6::TRP1, [URE3] 
